\title{
PEMBELAJARAN PERKUSI PADA EKSRAKURIKULER MARCHING BAND DI MAN 1 MEDAN
}

\author{
Oleh \\ MUHAMMAD RIZKI HABIBI.
}

\begin{abstract}
In Extracurricular Learning Percussion Marching Band in MAN 1 Medan. Faculty of Language and Arts University of Medan in 2015. This study aims to determine the learning percussion in extracurricular Marching Band in MAN 1 Medan, Iskandar Wlliam road no. 7B Medan. The experiment was conducted in February and March 2015. The method used in this research is descriptive qualitative method. Samples in this study are all members of the percussion players and coaches totaled 14 people, amounting to one person percussion. Data collection was conducted by literature study and field observations are interviews and documentation. Once all the data collected, the data is analyzed to answer all questions researchers. Analysis of the data presented in the form of descriptive gradually in writing, then classified according to content or material concerned shall. After the analysis conducted found that the learning outcomes percussion applied by coaches in extracurricular Marching Band MAN 1 The terrain is very nice and helpful for students. The students can read music well, signs of musical expression, know tempo. Courage and discipline of the students are also well embedded, so that the target which is expected by the coach and the school can achieve its full potential.
\end{abstract}

Keyword : Extracurricular Learning Percussion Marching Band in MAN 1 Medan 


\section{PENDAHULUAN}

Sekolah merupakan lembaga pendidikan yang bertujuan untuk mengembangkan potensi diri dalam berbagai disiplin ilmu. Lembaga pendidikan ini memberikan pengajaran secara formal. Berbeda hailnya dengan keluarga dan masyarakat yang memberikan pendidikan secara formal. Menurut pengertian umu, sekolah adalah sebagai tempat mengajar dan belajar. Pembelajaran merupakan proses dari yang tidak bisa menjadi bisa menjadi bisa, dapat diartikan untuk menjadikan murid memiliki kemampuan dan pengetahuan yang diharapkan. Pengertian ini menjelaskan bahwa pembelajaran merupakan setiap upaya yang dilakukan dengan sengaja oleh pendidik yang dapat menyebabkan peserta didik melakukan kegiatan belajar. Proses inilah yang menjadikan murid dapat belajar dengan baik. Pembelajaran music di Indonesia saat ini berkembang cukup baik, terbukti dengan bertambahnya sekolah music formal dan non formal. Berbagai macam cara diciptakan dalam mengajar agar efektif, seperti buku musik yang bergambar dan berwarna, partitur dan berbagai macam lainnya. Namun ada juga guru music yang tidak mengajar sesuai bidangnya karena kurangnya tenaga pengajar dalam bidang musik. Hal ini dapat diatasi dengan kreatifitas lebih yang dimiliki guru tersebut sehingga ilmu yang dapat disampaikan dapat diterima dengan baik oleh murid.

Marching Band di sekolah merupakan salah satu pendidikan yang tidak termasuk dalam kurikulum melainkan kegiatan ekstrakurikuler yang dilakukan di luar jam pelajaran, bertujuan untuk dapat mengembangkan bakat yang dimiliki masing-masing siswa. Pembelajaran dasar Marching Band dibagi menjadi dua kelompok yaitu kelompok besar dan kecil, masingmasing kelompok memiliki instrumen perkusi dan melodi. Instrumen perkusi yang terdapat di kelompok besar terdiri dari snare drum, multitom, bass drum, cymbals. Sedangkan instrumen melodinya terdiri dari glockenspiel ldan trumpet, mellophone, baritone dan tuba. 
Marching Band memiliki unsur-unsur yang terkandung dalam pembelajaran pada anak, diantaranya melatih kedisiplinan diri sendiri seperti menghafal materi yang disampaikan guru. Sehingga pada pertemuan berikutnya anak tetap mengingat materi yang disampaikan di pertemuan sebelumnya.Unsur yang kedua yakni menumbuhkan rasa kepemimpinan pada anak. Contohnya anak dapat memimpin teman-temannya dalam berbaris, memberi aba-aba, serta mengendalikan tempo dan irama dalam pertunjukan Marching Band. Unsur berikutnya yakni memupuk rasa keberanian dan kepercayaan diri saat tampil di depan orang banyak. Dan unsur yang terakhir adalah dapat menumbuhkan rasa kreatifitas pada diri anak karena pembelajaran dalam Marching Band menuntut anak untuk mengekspresikan diri pada saat bermain. Oleh sebab itu, pembelajaran Marching Band harus memiliki guru yang berkualitas dalam segi pengetahuan dan cara mengajar agar unsur-unsur dalam pembelajaran Marching Band dapat tercapai. Guru Marching Band sebaiknya memiliki cara yang kreatif dalam mengajar, guru juga harus mempunyai wibawa dan mudah disenangi siswa. Serta dapat memberi contoh yang baik karena anak akan meniru apa yang dilakukan gurunya. Dan yang paling penting seorang guru Marching Band harus sabar dalam menghadapi siswa.

Adapun alat musik Marching Band yang paling banyak diminati oleh siswa-siswi adalah devisi alat perkusi, bahkan hampir di setiap kejuaraan Marching Band diselipkan mata lomba battle percussion. Pada battle percusion, unit-unit Marching Band diadu devisi perkusinya saja, didalam perlombaan ini pemain perkusi menunjukan teknik-teknik dan kemampuannya dalam bermain perkusi. Perkusi adalah alat musik pukul, baik menggunakan stik maupun tangan, tetapi dalam Marching Band, perkusi dimainkan dengan menggunakan stik. Alat-alat perkusi dibawa atau disandang di badan dengan menggunakan carrier atau sering disebut dengan harnies.

$$
\text { Di dalam pembelajaran }
$$
perkusi ada beberapa teknik dasar 
yang harus dikuasai oleh pemain perkusi, misalnya cara pemegangan stik, sikap yang benar saat membawa alat, jenis-jenis pukulan dasar serta proses berjalan sambil membawa alat perkusi. Pada umumnya seorang pelatih perkusi di Medan sering melatih menggunakan partitur (notasi), bahkan ada juga pelatih yang melatih perkusi dengan cara manual tanpa menggunakan partitur sama sekali, namun tidak selamanya proses pembelajaran tersebut dapat berjalan dengan lancar. Hal ini dikarenakan oleh berbagai faktor, salah satunya adalah karena daya tangkap para siswa yang berbedabeda dalam memahami notasi, tempo, lambang-lambang notasi dan dinamika. Aktifitas Marching Band idealnya dilakukan dua kali seminggu selama 2 jam per pertemuan. Dengan pertemuan yang singkat tersebutlah harus diterapkan cara dan metode pembelajaran yang tepat oleh pelatih agar proses pembelajaran berjalan dengan lancar dan mendapatkan hasil yang maksimal

Berdasarkan uraian di atas penulis tertarik untuk mengetahui bagaimana proses pembelajaran perkusi pada ekstrakurikuler Marching Band di MAN 1 Medan, karena devisi perkusi Marching Band MAN 1 Medan sering mengikuti kejuaraan battle percussion dan mendapatkan prestasi yang cukup baik, dengan judul "Pembelajaran Perkusi Pada Ekstrakurikuler Marching Band Di MAN 1 Medan".

Adapun tujuan yang dapat disimpulkan dari latar belakang masalah diatas yaitu :

1. Apa latar belakang dibentuknya ekstrakurikuler Marching Band di MAN 1 Medan. 2. Teknik apa saja yang diajarkan pelatih dalam pembelajaran permainan perkusi pada ekstrakurikuler Marching Band MAN 1 Medan. 3. Metode mengajar apa yang diterapkan dalam pembelajaran perkusi pada ekstrakurikuler Marching Band MAN 1 Medan. 4.Apa saja faktor pendukung dan penghambat dalam proses pembelajaran perkusi pada ekstrakurikuler Marching Band di MAN 1 Medan. 5. Bagaimana hasil pembelajaran pada permainan 
perkusi ekstrakurikuler Marching Band MAN 1 Medan.

\section{PENGERTIAN PEMBELAJARAN}

Pengertian pembelajaran menurut Sugandi, dkk (2004:9) adalah: "Pembelajaran adalah terjemahan dari kata "instruction" yang berarti self instruction (dari internal) dan eksternal instructions (dari eksternal). Pembelajaran yang bersifat eksternal antara lain datang dari guru yang disebut teaching atau pengajaran. Dalam pembelajaran yang bersifat eksternal prinsipprinsip belajar dengan sendirinya akan menjadi prinsip-prinsip pembelajaran".

Sedangkan menurut Menurut Waldi (2005:39) menyatakan bahwa: "Pembelajaran adalah perpaduan dari dua aktivitas, yaitu aktivitas mengajar dan aktivitas belajar. Aktivitas mengajar menyangkut peranan seorang guru dalam konteks mengupayakan terciptanya jalinan komunikasi harmonis antara pengajar itu sendiri dengan si belajar sehingga didapatkannya kemampuan baru" Berdasarkan dua pengertian di atas dapat disimpulkan bahwa pembelajaran adalah proses antara dua pihak yang berbeda yang menyebabkan pengubahan pola pikir dan perilaku pihak yang terkait.

\section{PENGERTIAN PERKUSI}

Instrumen perkusi pada dasarnya merupakan benda apapun yang dapat menghasilkan suara baik karena dipukul, dikocok, digosok, diadukan, atau dengan cara apapun yang dapat membuatgetaran pada benda tersebut. Istilah instrument perkusi biasanya digunakan pada benda yang digunakan sebagai pengiring dalam suatu permainan musik.

Menurut James (1978:195): "Alat musik perkusi (disebut pula alat musik pukul atau tabuh) adalah alat musik yang menghasilkan suara dengan dipukul, ditabuh, digoyang, digosok, atau tindakan lain yang membuat objek bergetar, baik dengan suatu alat, tongkat, maupun dengan tangan kosong. Kata ini berasal dari istilah latin percussion (yang berarti memukul) dan percussion (kata bendayang berarti "PUKULAN")". 
Berdasarkan penjelasan di atasdapat disimpulkan bahwa perkusi adalah alat musik yang dimainkan dengan cara dipukul, dikocok, digosok atau diadukan sesuai jenis alat musik tersebut.

\section{PERKUSI CORP STYLE}

Seiring berjalannya waktu perkembangan perkusi juga semakin maju baik dari segi perlatan maupun teknik yang digunakan. Dahulu alat perkusi terbuat dari timah atau kaleng serta menggunakan membran yang terbuat dari kulit atau plastik Sekarang alat perkusi menggunakan babet dan besi serta menggunakan membran yang terbuat dari keplar yang sangat kuat.Alat perkusi yang dahulu dibawa dengan menggunakan tali sekarang alat perkusi sudah menggunakan harnis (carrier).

Pendapat Kirnadi (2011:90) yaitu : "Perubahan besar telah terjadi pada perkusi Marching Band dan sekarang memiliki nama perkusi corps style, suara masing-masing peralatan distel/di-tune sesuai dengan tone colour komposisi yang dibutuhkan. Ciri pokok "the marching tonal percussion" adalah permainan yang ritmik, dinamis, rumit serta mencakup banyak aspek teknik."

\section{TEKNIK DAN ALAT YANG} UMUM DIGUNAKAN DALAM BERMAIN PERKUSI

Teknik umum dalam bermain perkusi adalah: Griping (cara memegang stick), Sticking (cara memainkan stick). Ada punAlat-alat umum dalam bermain perkusi adalah: Snare Drum, Multitom, Bass Drum, Cymbals.

\section{TEKNIK KHUSUS BERMAIN PERKUSI}

Stick heights (Ketinggian Stick), Posisi Stick, Single Stroke, Double Stroke, Triple Stroke, Triplet (paradidale), Paradidaldidale

\section{PENGERTIAN}

\section{EKSTRAKURIKULER}

\section{(PENDIDIKAN NONFORMAL)}

Menurut UU No.2 Tahun 1989 dan PP No.73 Tahun 1991, pendidikan diselenggarakan melalui dua jalur, yaitu jalur sekolah dan jalur luar sekolah. Pendidikan nonformal adalah pendidikan yang diselenggarakan di luar jalur (atau 
sistem) pendidikan sekolah, baik dilembagakan maupun tidak dilembagakan, yang tidak harus berjenjang dan berkesinambungan.

Menurut Trisnamansyah (2007):

Pendidikan non formal (nonformal education) menurut Coombs, adalah setiap kegiatan pendidikan yang diorganisasikan di luar sistem persekolahan yang mapan, dilakukan secara sengaja untuk melayani peserta didik tertentu guna mencapai tujuan belajarnya atau sering disebut ekstrakurikuler.

Dapat disimpulkan bahwa pendidikan nonformal yang diselenggarakan di masyarakat pada lembaga yang membantu peserta didik di masyarakat sehingga selalu belajar tentang nilai, sikap, pengetahuan, dan keterampilan fungsional yang diperlukan untuk mengaktualisasikan diri dan mengembangkan masyarakat serta bangsa dengan selalu berorientasi pada kemajuan kehidupan masa depan.

PENGERTIAN MARCHING

\section{BAND}

Marching Band lahir pada pasca perang dunia II yang bermula dari prakarsa para veteran perang dunia kedua untuk mengenang patriotisme mereka. Bersama-sama dengan generasi muda yang ada dilingkungannya, mereka membentuk corps musik dengan memainkan lagu-lagu mars nostalgia perang dunia II, maka kegiatan ini berkembang dan menjadi popular. Mereka bermain musik mengenakan seragam ala militer lengkap dengan epolet-epolet berbaris keliling kota dengan bangganya.

Kirnadi (2011:13) mengemukakan bahwa: "Marching berasal dari bahasa inggris. Marching band artinya bergerak atau berjalan, sedangkan band artinya musik atau kumpulan musik. Jadi Marching Band artinya musik yang bergerak'.

Dapat disimpulkan bahwa Marching Band adalah suatu kegiatan musik yang dipergunakan bagi kepentingan baris berbaris atau sekumpulan orang yang memainkan musik dalam barisan pada perkembangan baik didalam parade maupun upacara ketentaraan, marching band mulai mamperkaya lagu, dan mulai membentuk harmoni baik dari seksi alat tiupnya. 


\section{LOKASI DAN WAKTU PENELITIAN}

Penelitian ini akan dilaksanakan di MAN 1 Medan jl. William Iskandar no.7B Medan. Penelitian dilaksanakan pada bulan Februari sampai Maret 2015.

\section{POPULASI PENELITIAN}

Populasi adalah himpunan individu atau objek yang banyaknya terbatas atau tidak terbatas (semua nilai), baik hasil perhitungan maupun pengukuran, baik kualitatif maupun kuantitatif dari pada karakteristik tertentu mengenai sekelompok objek yang jelas dan lengkap. Hal inisesuai dengan pendapat I Made. Wirartha (2006:40) yang mengemukakan bahwa: "populasi merupakan himpunan dari semua unit penelitian yang mungkin.Populasi penelitian harus dinyatakan sedemikian rupa sehingga tidak menimbulkan salah pengertian".

\section{Sugiyono}

(2008:117)

menyatakan bahwa "Populasi adalah wilayah generalisasi yang terdiri atas objek atau subjek yang mempunyai kualitas dan karakteristik tertentu yang ditetapkan oleh peneliti untuk dipelajari dan kemudian ditarik kesimpulannya". Sedangkan menurut Ridwan (2002:3) bahwa : "populasi adalah keseluruhan dari karakteristik atau unit hasil pengukuran yang menjadi objek penelitian.”.Populasi juga bukan sekedar jumlah yang ada pada objek/subjek yang dipelajari, tetapi meliputi seluruh karakteristik atau sifat yang dimiliki oleh subjek/objek itu.

Maka dari keterangan diatas dapat ditarik kesimpulan Populasi dalam penelitian ini adalah para siswa pemain perkusi dalam kegiatan ekstrakurikuler Marching Band di MAN 1 Medan, yang berjumlah 14 orang dan 1 orang pelatih.

\section{SAMPEL PENELITIAN}

Dalam menentukan sampel penelitian, peneliti berpedoman kepada pendapat Arikunto (2002:131) yang mengatakan bahwa"apabila jumlah subjektif kurang dari 100 orang, lebih baik diambil semua sehingga penelitianya merupakan penelitian populasi." Maka dari penjelasan diatas dapat ditarik kesimpulan Sampel dalam penelitian ini adalah seluruh 
siswa pemain perkusi dan pelatih perkusi berjumlah 14 orang. Sehingga penelitian ini disebut penelitian populasi, yang terdiri dari:

4. orang pemain snare, 1 orang pemain multitom, 4 orang pemain cymbals, 4 orang pemain bass drum, 1 orang pelatih

\section{METODE PENELITIAN}

Metode dalam penelitian ini adalalah deskriptif kualitatif, Dalam penelitian ini penulis akan menelusuri berbagai fakta dengan interprestasi yang tepat sesuai dengan kondisi yang berlangsung. Pelaksanaan penelitian deskriptif kualitatif tidak terbatas pada pengumpulan dan penyusunan data, tetapi meliputi analisis dan interprestasi data-data.

\section{TEKNIK PENGUMPULAN DAN}

\section{ANALISIS DATA}

Teknik pengumpulan dan analisis data dilakukan dengan 3 cara, yaitu: Studi Kepustakaan, Observasi lapangan, terdiri dari: Wawancara dan Dokumentasi.

\section{HASIL PENELITIAN}

\section{A. Latar Belakang Dibentuknya Ekstrakurikuler Marching Band MAN 1 Medan}

Terbentuk pada tanggal 10 Oktober 1987 dengan nama Gita Bahana Laksamana Safarina MAN 1 Medan, dibina oleh bapak kepala sekolah MAN 1 Medan pada saat itu, yaitu bapak Drs. Mukhtar Gafar serta dilatih oleh perwira TNI Angkatan Laut. Program awal Gita Bahana Safarina MAN 1 Medan adalah pengiring upacara bendera dan untuk kegiatan intern sekolah lainnya, serta kegiatan hari-hari besar di kota Medan. Di bawah kepelatihan Ahmad Bengar (UNIMED), Gita Bahana Laksamana Safarina MAN 1 Medan berubah nama menjadi Wings MANSA. Di masa beliau, Wings MANSA banyak mengalami penurunan kualitas karena berbagai faktor intern tim.

Puncaknya, Ahmad Bengar mengundurkan diri dan Wings MANSA mengalami kekosongan pelatih hingga lebih kurang 1 tahun. Posisi pelatih akhirnya diisi oleh Didi Handoko, Fauzi Syahputra dan Rangga yang merupakan alumni 
Wings MANSA. Wings MANSA kembali diubah namanya menjadi Gita Bahana Laksamana Safarina MAN 1 Medan. Keadaan Safarina mulai membaik. Karena alasan pribadi, pada tahun 2010 pelatih Didi Handoko mengundurkan diri. Kekosongan posisi pelatih digantikan oleh Muhammad Rizki Habibi yang merupakan alumni Safarina. Safarina di bawah asuhan ketiga pelatih tersebut mengalami kemajuan yang signifikan. Keadaan ini belangsung hingga penelitian ini dilaksanakan.

\section{B. TEKNIK PEMBELAJARAN PERKUSI, TERBAGI 2 YAITU:}

Griping (cara memegang stick)

Fauzi selaku pelatih perkusi menyatakan bahwasetiap siswa baru harus mengenali hal yang paling dasar sekali seperti cara memegang stick didalam Marching Band. Didalam Marching Band memegang stick menggunakan teknik griping tradisional, tetapi didalam materimateri tertentu juga menggunakan griping modern. Makan siswa harus dapat membedakan dan menguasai griping Tradisional dan griping modern.

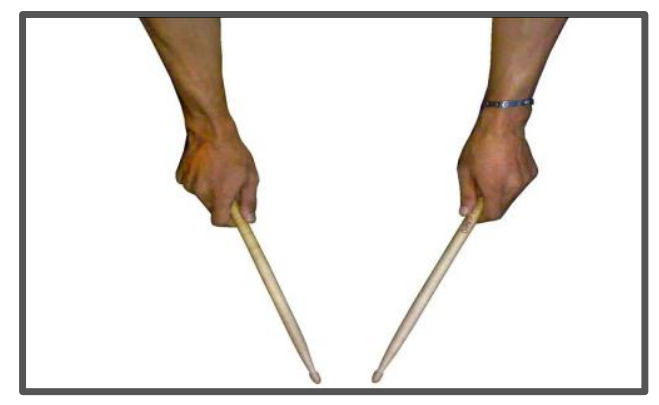

Gambar 4.1. Cara memegang Stik Griping Tradisional

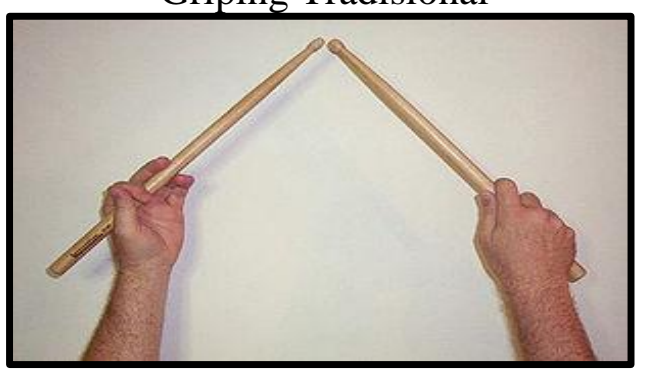

Gambar 4.2. Cara memegang Stik Griping Modern

Variasi teknik Partitur

\section{Metode pembelajaran Perkusi pada Ekstrakurikuler Marching Band MAN 1 Medan terbagi 2, yaitu:}

1. Metode Partitur

Metode Partitur adalah tulisan yang digunakan oleh pelatih atau instruktur untuk menyajikan not lagu yang akan dibahas. Setiap pemain perkusi diberikan partitur sebagai catatan untuk pedoman saat berlatih. Setelah semua anggota mendapat catatan partitur, pelatih membacakan 
notasi atau irama di depan pemain secara klasikal. Lalu para pemain secara bergantian dibimbing oleh pelatih untuk membaca partitur dengan tepat.

\section{Metode Demonstrasi}

Metode Demonstrasi adalah metode pembelajaran dimana pelatih atau instruktur memberikan contoh secara langsung di depan pemain perkusi. Pelatih mendemostrasikan cara memaikan pukulan yang dipelajari dengan melihati partitur kemudian siswa meniru pukulanpukulan pelatih. Setelah semua sesi alat perkusi menguasai materi yang didemostrasikan pelatih baru seluruh pemain perkusi bermain bersamasama sesuai dengan alatnya masingmasing.

\section{Metode Audiovisual}

Metode audiovisual adalah suatu cara dalam menyajikan bahan materi perkusi dengan menggunakan perekam suara seperti MP3. Pelatih menerapkan metode ini dengan tujuan agar tiap-tiap anggota dapat mengulangi materi sekaligus untuk pengingat jika siswa lupa dengan ritme pukulan dan memahami materi lebih dalam di rumah masingmasing.

\section{Hasil Pembelajaran Perkusi Marching Band MAN 1 Medan, adalah:}

1. Para anggota perkusi Marching Band MAN 1 mampu menguasai materi yang diberikan pelatih sesuai dengan waktu yang ditargetkan.

2. Marching Band MAN 1 Medan berhasil memenangkan beberapa event-event kejuaraan, diantaranya juara I Drum Battle pada kejuaraan Raja Majestic 2013 juara II Pekan Inovasi di Lapangan Merdeka tahun 2013, juara III Event Antibasi di UISU tahun 2013 dan lain-lain.

\section{E. Faktor penghambat dan pendukung dalam proses pembelajaran ekstrakurikuler Marching Band MAN 1 Medan}

1. Faktor Penghambat, yaitu: a. Banyaknya tugas sekolah. b. Jadwal les tambahan yang bersamaan dengan jadwal latihan. c. Sulitnya orang tua memberikan izin kepada anaknya jika jadwal latihan terlalu larut. d.Beberapa guru memarahi siswa mengikuti latihan. e.Sempitnya lokasi latihan 
2. Faktor Pendukung, yaitu:

a. Alat Marching Band memadai dan memenuhi standar untuk mengikuti perlombaan. b. Pihak sekolah selalu mendukung dan memfasilitasi keikutsertaan Marching Band dalam mengikuti lomba. c. Pelatih cenderung meng-upgrade perkembangan baru tentang perkusi.

\section{PENUTUP}

Berdasarkan hasil penelitian dan pembahasan yang telah diuraikan diatas, maka dapat diambil kesimpulan yaitu :

1. Marching Band MAN 1 Medan adalah salah satu program ekstrakurikuler yang terbentuk pada tanggal 10 Oktober 1987. Nama awal Marching BandMAN 1 Medan adalah Gita Bahana Laksamana Safarina MAN 1 Medan yang dipimpin oleh bapak kepala sekolah Drs. Mukhtar Gaffar sebagai pelopor pendirinya Marching Band di MAN 1 Medan. Pelatih
Marching Band pertama Gita Bahana Laksaman Safarina direkrut langsung dari TNI AngkatanLaut.Program kegiatan Marching Band MAN 1 Medan yang paling utama adalah sebagai pengiring upacara bendera dan untuk kegiatan intern sekolah, serta kegiatan di hari-hari besar di kota Medan. Diluar dari kegiatan rutin tersebut Marching Band ini juga dapat mengikuti perlombaan, tetapi tidak terlalu aktif. Seiring berjalannya waktu, banyak terjadi pertukaran pelatih dan pada akhirnya ekstrakurikuler Marching Band dibina oleh Didi Handoko, Fauzi Syahputra dan Rangga yang berasal dari alumni Marching Band MAN 1 Medan.Pada masa Didi Handoko sebagai kepala pelatih, beliau mengubah kembali nama Wings MANSA menjadi Gita Bahana Laksamana Safarina Man 1 Medan. Semenjak dilatih oleh Didi dan teman-teman keadaan safarina mulai membaik. Karena ada alasan pribadi kepala pelatih Didi mengundurkan diri dan 
digantikan oleh M. Rizki

Habibi.Dibawah kepelatihan

dengan formasi yang baru ini,

Safarina mulai menunjukan

eksistensinya kembali dan

memenangkan event-event

perlombaan. Keadaan ini

berlangsung hingga sekarang

2. Terdapat 2 teknik yang dipakai dalam proses pembelajaran Marching Band perkusi MAN 1

Medan, yaitu:

a. Teknik Dasar, terdiri dari:

- Griping (cara memegang stick) dan

- Sticking (cara memainkan stick) yaitu single stroke, double stroke, dan triplet stroke.

b. Teknik Variasi, terdiri dari:

- New Bucks

- $\quad$ Timing

- Seivac

3. Dalam proses pembelajaran perkusi Marching Band MAN 1 Medan menggunakan 3 metode yaitu:

a. Metode partitur, dan

b. Metode demonstrasi

c. Metode Audio Visual
4. Hasil pembelajaran perkusi Marching Band MAN 1 Medan yaitu:

a. Para anggota perkusi Marching Band MAN 1 Medan mampu menguasai materi yang diberikan pelatih sesuai dengan waktu yang ditargetkan.

b. Marching Band MAN 1 Medan berhasil memenangkan beberapa event -event kejuaraan, diantaranya juara I Drum Battle pada kejuaraan Raja Majestic 2013, juara II Pekan Inovasi di Lapangan Merdeka tahun 2013, juara III Event Antibasi di UISU tahun 2013 dan lainlain.

5. Faktor penghambat dan faktor pendukung dalam pembelajaran perkusi.

a. Faktor penghambat yaitu sebagai berikut:

- Banyaknya tugas sekolah.

- Jadwal les tambahan yang bersamaan dengan jadwal latihan.

- Sulitnya orang tua memberikan izin kepada 
anaknya jika jadwal

latihan terlalu larut.

- Beberapa guru memarahi siswa mengikuti latihan

- Sempitnya lokasi latihan

b. Faktor pendukung yaitu sebagai berikut:

- Alat Marching Band memadai dan memenuhi standar untuk mengikuti perlombaan.

- Pihak sekolah selalu mendukung dan memfasilitasi

keikutsertaan Marching

Band dalam mengikuti lomba.

- Pelatih cenderung mengupgrade perkembangan baru tentang perkusi.

\section{SARAN}

Berdasarkan hasil penelitian ini, peneliti mengajukan beberapa saran sebagai berikut:

1. Kepada kepala sekolah MAN 1 Medan agar lebih memperhatikan sarana dan prasarana sekolah agar setiap kegiatan ekstrakurikuler dapat berjalan dengan baik dan maksimal khususnya kegiatan ekstrakurikuler Marching Band.

2. Kepada pelatih Marching Band khususnya pelatih perkusi agar melaksanakan kegiatan pembelajaran sesuai dengan jadwal yang telah ditetapkan, agar pembelajaran menjadi ebih efektif.

3. Kepada para dewan guru agar lebih mendukung kegiatan yang telah dicanangkanoleh pihak sekolah agar siswa siswi lebih nyaman untuk menggembangkan bakatnya tanpa ada tekanan.

4. Kepada orang tua diharapkan agar selalu mendukung bakat dan minat anak dan ikut berperan dalam kegiatan ekstrakurikler, khususnya ekstrakurikuler Marching Band.

5.

\section{DAFTAR PUSTAKA}

Abdulhak Ishak, M.Pd. Prof. Dr. H. 2012, PenelitianTindakan Dalam Pendidikan Nonformal. Jakarta : Raja Grafindo. 
Albercht, Sally K. (Y.th). The Choral Warm-Up Collection; A Sourcebook of 167 Choral warm-ups Contributed by 51 Choral Directorors. CA: Alfred Publishing Co.,Inc.

Aziz Alimut, Hidayat (2007), Metode Penelitian kelebihan dan tekhnik Analisa Data, Surabaya : Salemba Media.

Buku Panduan. Unimed.2010. Buku Pedoman Universitas Negeri Medan.Medan, 2010.

George Liddell, Henry anda scott, robert, Oxford, A Greek English Lexion. London: Clarendon Press.

Hamalik, Oemar. 2009. Kurikulum dan Pembelajaran. Jakarta: Bina Angkasa.

Jamess Hollad, 1978.Percusion

Kirnadi, 2011. Dunia Marching Band

Maryeni. 2005. Metode Penelitian Kebudayaan. Jakarta : Bumi Akasara.

Muttaqin, Moh.2008. Musik Klasik (Pengantar Musikologi untuk SMK). Jakarta: Pusat Perbukuan Pendidikan Nasional.

Margeretha Widian. 2011. Kontribusi Model Pembelajaran Kooperatif Pada Pembelajaran Ansambel Campuran Siswa Kelas VII-I SMP Swasta Free Methodist 1 Helvetia Medan.
Priyatna. 1987. Marching Band Sebagai Satu Seni Dan Perkembangan Di Indonesia. Bandung.

Sanjaya Wina, M. Pd. Dr. 2006. Strategi pembelajaran. Bandung : Kencana.

Soehartono.2002.Metode penelitian Sosial, Bandung : Remaja Rodakarya.

Soeharto, M.1992. Kamus Musik. Jakarta: Gramedia Widiasarana Medan

Sutopo.2002, Metode Penelitian Kualitatif, Bandung : Alfabeta.

Supranto.2004.Memahami Penelitian Kualitatif, Bandung : Alfabeta

Sugiono (2011). Metode Penelitian Pendidikan, Bandung : Alfabeta.

Tambunan H.A. Marthin. 2010, Struktur Musik, Penggunaan, Dan Fungsi Marching Band. Canka Dhira Dharma Yon Zipur I/Dd

WikiPedia Indonesia.2013 :http /II id.wikipedia. org /wiki/ Harmoni.com

Zakaria, 2003. Dengan Judul Skripsi :" Study Kooperatif Marching Band Unimed Dan Marching Band MAN 1 MEDAN. 